\title{
Studies on crystal structures, optical and electrical properties of viologen cation salts of $\mathbf{d}^{10}$ metal halide anions $\uparrow$
}

\author{
Haijuan Du, ${ }^{\mathrm{a}}$ Yaru Li, ${ }^{\mathrm{b}}$ Manman $\mathrm{Xu},{ }^{\mathrm{a}}$ Yunyin Niu ${ }^{* a}$ and Hongwei Hou ${ }^{* a}$ \\ ${ }^{a}$ College of Chemistry and Molecular Engineering, Zhengzhou University, Zhengzhou \\ 450001, P. R. China \\ ${ }^{\mathrm{b}}$ Department of Anesthesiology, The First Affiliated Hospital, Zhengzhou University, \\ Zhengzhou 450001, P. R. China
}

\begin{abstract}
Construction of viologen cation salts of $\mathrm{d}^{10}$ metal halide anions (inorganic-organic hybrid materials) with semiconducting properties via supramolecular design and aggregate enable the hybrid materials multifunctionality. Our interest focused on the use of the viologen derivatives as the building units because they were redox-active units and more suited to yield new generation of multifunctional networks. In the present investigation, three new inorganic-organic hybrid semiconductors $\left\{\left[\text { bbpyb] } \cdot\left[\mathrm{AgBr}_{3}\right]\right\}_{\mathrm{n}}(\mathbf{1})[1,3-\mathrm{PMBP}]\left[\mathrm{Zn}_{2} \mathrm{Cl}_{5.1} \mathrm{Br}_{0.9}\right]\right.$ (2) and [1, 3-PMBP] $\left[\mathrm{Zn}_{2} \mathrm{Br}_{6}\right]$ (3) (bbpyb = 1,1"-(1,4-butanediyl)bis[4,4'-bipyridinium]bis[bromide], 1,3-PMBP = 1,1'-[1,3-phenylene-bis(methylene)]bis-4,4'-bipyridinium-bisbromide) were synthesized. More importantly, great efforts were devoted to investigate their properties, such as optical and electrical properties. 1-3 exhibited photochromism, which can be ascribed to the intermolecular charge transfer to yield radicals. Fabricating the appropriate inorganic and organic units controllably within photosensitive materials at a molecular level is critical for the development of new photochromic inorganic-organic hybrids.
\end{abstract}

Keywords: multi-functional hybrid materials; semiconducting properties; supramolecular; self-assembly; optical and electrical properties

*Corresponding author.

E-mail: $\underline{\text { niuyy@zzu.edu.cn, houhongw@zzu.edu.cn }}$ 


\section{Introduction}

Over the past decade, great efforts have been made in developing and assembly multi-functional hybrid materials and exploring their potential applications [1]. Meanwhile, it is expected to enable the hybrid materials multifunctionality, which not only because of their potential higher economic values, but also for their broader application scope relative to a single functional materials [2]. Of these, the rational design and assembly of inorganic-organic hybrid semiconductor based on their inorganic and organic counterparts is opening up new multifunctional materials for structural diversity and interesting optical, electrical and magnetic properties [3]. And incorporation and integration of the two inorganic and organic counterparts into hybrids possess the optical, electrical, and environmental durability of inorganic materials, and the mechanical flexibility and properties tunability of $\pi$-electron organics [4]. Recently, much research interest has been focused on the construction of inorganic-organic hybrid materials with semiconducting properties via supramolecular design and aggregates [5]. These supramolecular interactions included ionic bonding, hydrogen bonds, van der Waals interactions and $\pi-\pi$ stacking intermolecular interactions etc, which provided chances for obtaining interesting and multifunctional supramolecular frameworks that may lead to different properties [1b, 6].

On one hand, the family of metal halides is an important one [7]. On the other hand, viologens (N,N'-disubstituted-4,4'-bipyridinium) are well known as electron acceptors in molecular assemblies and possess excellent properties such as electronic and molecular devices, solar energy storage and organic electrical conductors [8-10]. Our interest focused on the use of the viologen derivatives as the building units because they were redox-active units and more suited to yield new generation of multifunctional networks [6b].

Recently we have reported a photochromic inorganic-organic hybrid $\{[1$, $\left.3-\mathrm{PMBP}] \cdot\left[\mathrm{AgBr}_{3}\right]\right\}_{\mathrm{n}}[11]$, which exhibited interesting multifunctional properties such as fast photochromic and photoluminescence behaviors. In order to further 
obtain more interesting structures and explore the multifunctionality of these materials, we choose the other one viologen derivative 1,1"-(1,4-butanediyl)bis[4,4'-bipyridinium]bis[bromide] to react with $\mathrm{AgBr}$ upon slow self-assembly from $\mathrm{DMF} / \mathrm{CH}_{3} \mathrm{OH}$ mixture systems to obtain new photochromic inorganic-organic hybrid $\left[(\mathrm{bbpyb})\left(\mathrm{AgBr}_{3}\right)\right]_{\mathrm{n}}(\mathbf{1})$, which shows thermally irreversible. Furthermore, the $\mathrm{AgBr}$ was replaced by $\mathrm{ZnCl}_{2}$ and $\mathrm{ZnBr}_{2}$ to react with 1,1'-[1,3-phenylene-bis(methylene)]bis-4,4'-bipyridinium-bisbromide upon slow self-assembly from $\mathrm{H}_{2} \mathrm{O} / \mathrm{CH}_{3} \mathrm{OH}$ mixture systems to form two new photochromic inorganic-organic hybrids [1, 3-PMBP] $\left.\mathrm{Zn}_{2} \mathrm{Cl}_{5.1} \mathrm{Br}_{0.9}\right]$ (2) and [1, 3-PMBP] $\left[\mathrm{Zn}_{2} \mathrm{Br}_{6}\right]$ (3), which are photosensitive to UV-Vis light irradiation and easily decolor after heating at $110{ }^{\circ} \mathrm{C}$ for $1.5 \mathrm{~h}$ in the air, respectively. Moreover, their electrical properties are also studied, which indicate that they have semiconducting behaviors.

\section{Experimental}

\subsection{Materials and methods}

The viologen derivative cationic compounds 1,1"-(1,4-butanediyl)bis[4,4'-bipyridinium]bis[bromide] $\quad\left([\mathrm{bbpyb}]^{2+}\right)$ and 1,1'-[1,3-phenylene-bis(methylene)]bis-4,4'-bipyridinium-bisbromide $\quad$ (1,3-PMBP) were synthesized according to the reported literature method [12]. Other chemicals were of reagent grade and used as purchased without further purification. The IR spectra were recorded on a Shimazu IR435 spectrometer as KBr disk (4000-400 cm $\left.{ }^{-1}\right)$. The purity of the bulk microcrystalline materials obtained from the syntheses was checked by Powder X-ray diffraction analysis. Powder X-ray diffraction (PXRD) patterns were recorded using $\mathrm{Cu} \mathrm{K} \alpha 1$ radiation on a PAN analytical X'Pert PRO diffractometer. Thermogravimetric analyses (TGA) were carried out on a model NETZSCHTG209 thermal analyzer in flowing $\mathrm{N}_{2}$ atmosphere of $20 \mathrm{~mL} \cdot \mathrm{min}^{-1}$ at a heating rate of $10{ }^{\circ} \mathrm{C} \cdot \mathrm{min}^{-1}$ in the temperature range $0-800{ }^{\circ} \mathrm{C}$ using platinum crucibles. The UV-Vis diffuse reflectance spectra (DRS) were recorded on a Cary $5000 \mathrm{UV}-$ Vis-NIR at the speed of $300 \mathrm{~nm} \cdot \mathrm{min}^{-1}$ from 800 to $200 \mathrm{~nm}$. The elemental 
composition of the compounds were analyzed by energy-dispersive X-ray spectroscopy (EDX) (Oxford Instruments, model $X-\operatorname{maxn}^{N}$ ) attached to the Zeiss Auriga scanning electron microscope. ESR spectra were recorded on a Bruker JEOL JES-FA200 spectrometer with a $100 \mathrm{kHz}$ magnetic field in $\mathrm{X}$ band at room temperature. The optical measurements were performed with linearly polarized $21 \mathrm{ps}$ pulses at $532 \mathrm{~nm}$ generated from a frequency-doubled Q-switched Nd:YAG laser, this wavelength is of paramount practical importance in the field of optical limiting as well as design and fabrication of resonance cavities of lasers. The spacial profiles of the pulses were nearly Gaussian after a spatial filter was employed. Electrical measurements were performed with an Im6 Zahner (Germany) electrochemical workstation.

\subsection{Compound synthesis}

[(bbpyb) $\left.\left(\mathbf{A g B r}_{3}\right)\right]_{\mathbf{n}} \mathbf{( 1 )}$. A methanol solution of [bbpyb].2Br $(26.4 \mathrm{mg}, 0.05 \mathrm{mmol})$ was added into a stirring solution of $\mathrm{AgBr}(9.4 \mathrm{mg}, 0.05 \mathrm{mmol})$ with the presence of excessive $\mathrm{KBr}$ (0.40-0.45 mmol) dissolved in $\mathrm{N}, \mathrm{N}$ - dimethylformamide (DMF). More DMF, otherwise more methanol, is needed if precipitation appears until the precipitation almost disappeared. The clear solution filtrated is to be slowly evaporated in a vial at ambient temperature and several days later yellow crystals suitable to X-ray diffraction, $\left\{\left[\text { bbpyb] } \cdot\left[\mathrm{AgBr}_{3}\right]\right\}_{\mathrm{n}}\right.$, were obtained in yield of $53 \%$ based on silver ions.

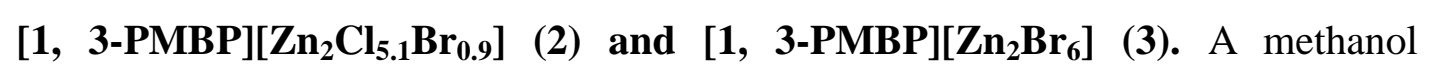
solution of [1, 3-PMBP] $2 \mathrm{Br}(28.8 \mathrm{mg}, 0.05 \mathrm{mmol})$ was added into a stirring solution of $\mathrm{ZnCl}_{2}(6.8 \mathrm{mg}, 0.05 \mathrm{mmol})$ or $\mathrm{ZnBr}_{2}(11.3 \mathrm{mg}, 0.05 \mathrm{mmol})$ with the presence of excessive $\mathrm{KBr}(0.40-0.45 \mathrm{mmol})$ dissolved in $\mathrm{H}_{2} \mathrm{O}$. More $\mathrm{H}_{2} \mathrm{O}$, otherwise more methanol, is needed if precipitation appears until the precipitation almost disappeared. The clear solution filtrated is to be slowly evaporated in a vial at ambient temperature and several days later yellow crystals suitable to X-ray diffraction, [1, 3-PMBP] $\left[\mathrm{Zn}_{2} \mathrm{Cl}_{5.1} \mathrm{Br}_{0.9}\right]$ were obtained in yield of $69 \%$ based on zinc ions, and [1, 
3-PMBP] $\left[\mathrm{Zn}_{2} \mathrm{Br}_{6}\right]$ were obtained in yield of $72 \%$ based on zinc ions.

\subsection{X-ray crystallography study}

Crystallographic data for the compounds were collected at $100(2) \mathrm{K}$ on a Bruker APEX-II area-detector diffractometer equipped with graphite-monochromatized Mo-Ka radiation $(\lambda=0.71073 \AA)$. Their structures were solved by direct method and expanded using Fourier techniques. The non-hydrogen atoms were refined with anisotropic thermal parameters. The hydrogen atoms were assigned with common isotropic displacement factors and included in the final refinement by using geometrical constraint. The structures were refined with full-matrix least-squares techniques on $\mathrm{F}^{2}$ using the OLEX-2 program package [13]. Crystal data for 1-3 were summarized in detail in Table 1. Selected bond lengths and bond angles were put in Table S1 (see the Supporting Information) The CCDC reference numbers are 1447387 for $\mathbf{1}, 1474478$ for $\mathbf{2}$ and 1474479 for $\mathbf{3}$.

\section{Results and discussion}

\subsection{Structural characterization}

Crystal structure of $\left[(\mathbf{b b p y b})\left(\mathbf{A g B r}_{3}\right)\right]_{\mathbf{n}}(\mathbf{1})$. The single crystal X-ray diffraction analysis shows that compound $\mathbf{1}$ crystallizes in the monoclinic space group $C 2 / c$. According to structural analysis, this structure is a $\left[\mathrm{AgBr}_{3}\right]_{\mathrm{n}}{ }^{2 \mathrm{n}-} 1-\mathrm{D}$ polymeric anion accompanied by discrete cations. As shown in Fig. 1a, The alkyl chain of the 1, 4-bis(4,4'-bipyridinium)butane dication existed in a (cis) $)_{4}$ conformation. Each bbpyb exhibits a bent geometry with the torsion angle of $170.44^{\circ}$ along the $\mathrm{C} 4$ bridging chain, and the dihedral angels between the aromatic rings of $3.509^{\circ}$. Each $\operatorname{Ag}(1)$ coordinates to two $\mu_{2}$ - $\mathrm{Br}(\mathrm{Ag} 1-\mathrm{Br} 1=2.944 \AA$ and $\mathrm{Ag} 1-\mathrm{Br} \# 1=2.944 \AA)$ and two $t$ - $\mathrm{Br}$ (Ag1- Br2 =2.618 $\AA$ and $\mathrm{Ag} 1-\mathrm{Br} 2 \# 1=2.618 \AA$ ). The distance between the Br1 atom of the inorganic component and the $\mathrm{N} 2$ atom of the organic component is $3.828 \AA$, in which electrons can transfer from the donor to the acceptor moieties favorably [6c, 14]. The 1D infinite polyhedral chain constructed by inorganic units was showed in 
Fig. 1b. As illustrated in Fig. 1c, the neighbouring bbpyb cations were threaded into a sunglasses-like frame in the $a b$-plane. And then, the inorganic units filled in the frame to form an intriguing supramolecular architecture by non-covalent interactions

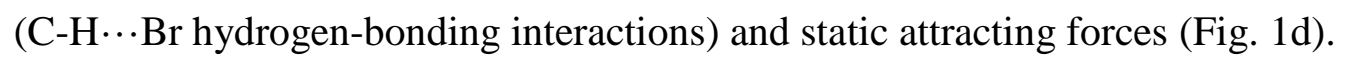

There also exist weak $\mathrm{C}-\mathrm{H} \cdots \mathrm{Br}$ hydrogen bonds from the inorganic moieties to the organic moieties similar to the reported literatures [15]. The distance between $\mathrm{Br} 2$ atom and $\mathrm{H} 2$ atom is $2.826 \AA$, the $\mathrm{Br} 2$ atom and $\mathrm{C} 2$ atom is $3.721 \AA$, with the $\mathrm{C} 2-\mathrm{H} 2 \cdots \mathrm{Br} 2$ angle of $161.896^{\circ}$; two weak $\mathrm{C} 2-\mathrm{H} 2 \cdots \mathrm{Br} 2$ hydrogen bonds between one cation and inorganic polyanion contribute to the formation of a gold ingod-like building block (Fig. 1e). And then, two other C9-H9 $\cdots$ Br1=2.711 $⿱$ A hydrogen bonds between two adjacent cation and inorganic polyanion formed a 1D inorganic-organic hybrid chain (Fig. 1f).

\section{Crystal structures of [1, 3-PMBP] $\left[\mathrm{Zn}_{2} \mathrm{Cl}_{5.1} \mathrm{Br}_{0.9}\right]$ (2) and [1, 3-PMBP] $\left.\mathrm{Zn}_{2} \mathrm{Br}_{6}\right]$}

3). Compounds 2-3 contain the same viologen derivative $[1,3-\mathrm{PMBP}]^{2+}$ as cation but different metal halides as anions: $\left[\mathrm{Zn}_{2} \mathrm{Cl}_{5.1} \mathrm{Br}_{0.9}\right]^{2-}$ for $\mathbf{2}$, and $\left[\mathrm{Zn}_{2} \mathrm{Br}_{6}\right]^{2-}$ for $\mathbf{3}$, respectively. It is interesting that $\left[\mathrm{Zn}_{2} \mathrm{Cl}_{5.1} \mathrm{Br}_{0.9}\right]^{2-}$ contained in compound $\mathbf{1}$, which may be because that the $\mathrm{Br}$ atoms were easier to be coordinated to metal $\mathrm{Zn}$ atoms than the $\mathrm{Cl}$ atoms.

Compound 2 crystallizes in the monoclinic space group $P 2_{1} / \mathrm{n}$. As shown in Fig. 2 a, viologen derivative [1, 3-PMBP] $]^{2+}$ in compound 2 exhibited in a "V" configuration, and the angle was $87.057^{\circ}$. And the dihedral angels between the aromatic rings were $22.963^{\circ}$ and $31.201^{\circ}$. Zn1 exhibited distorted tetrahedron-like geometry, coordinated by $\mathrm{Cl} 1, \mathrm{Cl} 2, \mathrm{Cl} 3$ (or $\mathrm{Br} 1$ ) and $\mathrm{N} 1$ atoms, with $\mathrm{Zn}-\mathrm{Cl}$ bond distances of 2.257(2)-2.318(1) $\AA$, Zn-Br bond distance of 2.333(1) $\AA$, Zn-N bond distance of 2.069(4) A. And Zn2 also exhibited distorted tetrahedron-like geometry, coordinated by $\mathrm{Cl} 4$ (or $\mathrm{Br} 2$ ), $\mathrm{Cl} 5$ (or $\mathrm{Br} 3$ ), $\mathrm{Cl} 6$ (or $\mathrm{Br} 4$ ) and $\mathrm{N} 4$ atoms, with $\mathrm{Zn}-\mathrm{Cl}$ bond distances of 2.289(1)-2.330(1) $\AA$, Zn-Br bond distances of 2.130(2)-2.383(6) $\AA$, Zn-N bond distance of 2.066(4) $\AA$. We can see from Fig. $2 b$ the neighboring discrete molecular structures formed a 1D inorganic-organic hybrid chain via some supramolecular 
interactions. And then they continued to expand into space to form intriguing supramolecular architecture (Fig. 2c).

Compound 3 crystallizes in the monoclinic space group $P 2_{1} / \mathrm{n}$. As shown in Fig. 3a, viologen derivative $[1,3-\mathrm{PMBP}]^{2+}$ in compound $\mathbf{3}$ also exhibited in a "V" configuration, and the angle was $88.211^{\circ}$. And the dihedral angels between the aromatic rings were $21.483^{\circ}$ and $31.367^{\circ}$. Both $\mathrm{Zn} 1$ and $\mathrm{Zn} 2$ exhibited distorted tetrahedron geometry. $\mathrm{Zn} 1$ coordinated by $\mathrm{Br} 1, \mathrm{Br} 2, \mathrm{Br} 3$ and N1, with $\mathrm{Zn}-\mathrm{Br}$ bond distances of 2.370(1)-2.398(1) $\AA$ and $\mathrm{Zn}-\mathrm{N}$ bond distance of 2.074(5) $\AA$. Zn2 coordinated by Br4, Br5, Br6 and N4, with $\mathrm{Zn}-\mathrm{Br}$ bond distances of 2.353(1)-2.391(1) $\AA$ and $\mathrm{Zn}-\mathrm{N}$ bond distance of 2.063(5) $\AA$. We can see from Fig. $3 b$ there also exist weak $\mathrm{C}-\mathrm{H} \cdots \mathrm{Br}$ hydrogen bonds from the inorganic moieties to the organic moieties similar to the reported literature [15]. The distance between $\mathrm{Br} 5$ atom and $\mathrm{H} 11 \mathrm{~B}$ atom is $2.772 \AA$, the $\mathrm{Br} 5$ atom and $\mathrm{C} 11$ atom is $3.709 \AA$, with the $\mathrm{C} 11-\mathrm{H} 11 \mathrm{~B} \cdots \mathrm{Br} 5$ angle of $162.578^{\circ}$; And then, two adjacent discrete molecular structures formed a 1D inorganic-organic hybrid chain via $\mathrm{C}-\mathrm{H} \cdots \mathrm{Br}$ hydrogen-bonding interactions (Fig. 3c). And then they continued to expand into space to form intriguing supramolecular architecture by supramolecular interactions (Fig. 3d).

In addition, the distances between the inorganic component (zinc halides) and the organic component (viologen derivatives) are $(\mathrm{Cl} \cdots \mathrm{N}) 3.395-3.608 \AA$ and $(\mathrm{Br} \cdots \mathrm{N})$ 3.273-3.643 $\AA$ for compound 2 and $(\mathrm{Br} \cdots \mathrm{N}) 3.461-3.630 \AA$ for compound 3 , in which electrons can transfer from the donor to the acceptor moieties favorably [6c, 14].

\subsection{Other characterizations}

The optical absorption spectra of 1-3 were measured by the UV-Vis diffuse-reflectance experiment to achieve their band gaps $\left(E_{\mathrm{g}}\right)$. The band gaps $\left(E_{\mathrm{g}}\right)$ were determined as the intersection point between the energy axis and the line extrapolated from the linear portion of the absorption edge in a plot of Kubelka-Munk function $F$ against energy $E$ [16]. The $F$ versus $E$ plot, as shown in Fig. S1, the $E_{\mathrm{g}}$ value assessed from the steep absorption edge were $2.00 \mathrm{eV}$ for $\mathbf{1}, 1.69 \mathrm{eV}$ for 2 and 
$1.76 \mathrm{eV}$ for $\mathbf{3}$, showing that the present compounds belong to semiconductors [17a] and the above-mentioned $\mathrm{E}_{\mathrm{g}}$ values further prove this conclusion [17b]. In order to examine the thermal stability of compounds $\mathbf{1}-\mathbf{3}$, thermal gravimetric (TG) analyses were carried out. The TG curve indicates that $\mathbf{1}$ is thermally stable up to $252{ }^{\circ} \mathrm{C}$. And over the range of $255-797{ }^{\circ} \mathrm{C}$, successive weight-loss process corresponds to the decomposition of organic cations and inorganic bulks for compound 1. And as the TG curves of compounds 2-3 shown, they exhibited close structures but different behaviours under heating. The thermostability of compound $\mathbf{3}$ was better than compound 2, which may be caused by the following: when the $\mathrm{Br}^{2-}$ anion coordinated to the $\mathrm{Zn}^{2+}$, the coordinated interactions were more stable (Fig. S2). PXRD patterns (Fig. S3-5) indicate that there is no obvious isomerization or dissociation after irradiation treatment. In addition, the experimental PXRD patterns 1-3 and 1p- 3p correspond well to the simulated PXRD patterns, indicating that the bulk phase materials are isomorphous. IR spectra of compounds 1-3 and 1p- 3p are shown in Fig. S6-8. Here, EDX survey spectra show all the expected elements (Fig. 4), which are in agreement with single crystal X-ray diffraction results.

\subsection{Photochromic properties}

Upon UV-vis light irradiation, compounds 1-3 (the photoproduct after irradiation named as 1p-3p) undergo an interesting photochromic transformation from yellow to green and using a $500 \mathrm{~W}$ Xe lamp (Fig. 5). Their coloration behaviors have been characterized by UV-vis diffuse-reflectance spectroscopy. After irradiation, the compound 1p-3p show the obvious color change and enhanced absorption in the UV-vis diffuse reflectance spectra at around $625 \mathrm{~nm}$ of $\mathbf{1 p}, 647 \mathrm{~nm}$ of $\mathbf{2 p}, 641 \mathrm{~nm}$ of 3p, which are similar to that of reported viologen radicals [6b-c, 14]. To further confirm the generation of radicals, the electron spin resonance (ESR) spectra of compounds 1-3 and 1p-3p were measured. ESR studies show that compound 1-3 exhibit no or extremely weak ESR signals before irradiation, however, compound 1p-3p present single line strong signal with $\mathrm{g}=2.00016, \mathrm{~g}=2.00003$ and $\mathrm{g}=1.9999$ after 
irradiation, respectively (Fig. 6), which are similar to other reported radicals [6b-c, 14]. Actually, the photoproduct $1 \mathbf{p}$ shows photic and thermal irreversible and is stable in the air after coloration, which may be classified as free radical semiconductor [18a-b]. However, it can be decolored by recrystallization [18c-e]. And then, the photoproduct $\mathbf{2 p}$ and $\mathbf{3 p}$ can be kept in the dark for several days, but they exhibit a bleaching phenomenon when they are heated at $110{ }^{\circ} \mathrm{C}$ for $1.5 \mathrm{~h}$ in the air. Their photochromism mechanism conformed to the reported mechanism by the Guo group [14]

\subsection{Third-Order NLO properties}

We revealed the nonlinear optical properties of these compounds by using a Z-scan technique [19]. The compound 1 (3.55 $\mathrm{mg})$ in $3 \mathrm{~mL}$ DMSO to be suspension liquid and pure DMSO were measured and shown in Fig. 7 and Fig. S9. The NLO absorption component was evaluated under an open-aperture configuration. The NLO absorption data can be well represented by eq (1) which described a third-order NLO process [20]. It clearly illustrated that the absorption increases as the incident light irradiance rose. The effective nonlinear absorptive index $\beta$ was estimated to $8 \times 10^{-12}$ $\mathrm{m} / \mathrm{W}$ for compound $\mathbf{1}$.

$$
\begin{aligned}
& \mathrm{T}(\mathrm{z})=\frac{1}{\sqrt{\pi \mathrm{q}(\mathrm{z})}} \int_{+-\infty}^{\infty} \ln [1+\mathrm{q}(\mathrm{z})] \mathrm{e}^{-\tau^{2}} \mathrm{~d} \tau \\
& \mathrm{q}(\mathrm{z})=\beta^{\text {eff }} I(\mathrm{z}) \stackrel{1-\mathrm{e}^{-\alpha_{0} \mathrm{~L}}}{\alpha_{0}}
\end{aligned}
$$

Where $\alpha_{0}$ and $\beta$ are linear and effective third-order NLO absorptive coefficients, $\tau$ is the time, and L is the optical path. Light transmittance (T) is a function of the sample's $\mathrm{Z}$ position (with respect to the focal point at $\mathrm{Z}=0$ ).

The NLO refractive properties were assessed by dividing the normalized Z-scan data obtained under the closed-aperture configuration by the normalized Z-scan data obtained under the open-aperture configuration. The refractive index $\gamma$ can be given by eq $2[20]$. 


$$
\gamma=\frac{\lambda \alpha_{0}}{0.812 \pi I\left(1-\mathrm{e}^{-\alpha 0 \mathrm{~L}}\right)} \Delta \mathrm{TV}_{\mathrm{P}}
$$

Where $\Delta \mathrm{T}_{\mathrm{V}-\mathrm{P}}$ is the difference between normalized transmittance values at valley and peak positions, $\alpha_{0}$ is the linear coefficient, L is the sample thickness, I is the peak irradiation intensity at focus and $\lambda$ is the wavelength of the laser. The refractive index $\gamma$ were calculated to be $1.7 \times 10^{-19} \mathrm{~m}^{2} / \mathrm{W}$ for compound $\mathbf{1}$.

Most of the well performing third-order NLO materials reported in the literature are solid materials (such as: semiconductors, conjugated polymers, etc.). Impressive NLO values for inorganic-organic hybrid semiconductors are achieved with a much diluted solution and much superior NLO performance can be expected if the solubilities can be improved significantly.

\subsection{Electrical property}

As above mentioned optical properties previously, meanwhile, the electrical properties of single crystals $\mathbf{1}$ - $\mathbf{3}$ were studied at variable temperature. Fig. 8 shows that the electrical conductivities of the $\mathbf{1}-\mathbf{3}$ increase from $1.36 \times 10^{-6} \mathrm{~S} \mathrm{~cm}^{-1}$ to $1.70 \times$ $10^{-4} \mathrm{~S} \mathrm{~cm}^{-1}, 1.90 \times 10^{-8} \mathrm{~S} \mathrm{~cm}^{-1}$ to $7.13 \times 10^{-8} \mathrm{~S} \mathrm{~cm}^{-1}$ and $3.24 \times 10^{-8} \mathrm{~S} \mathrm{~cm}^{-1}$ to $1.13 \times$

$10^{-7} \mathrm{~S} \mathrm{~cm}^{-1}$ in the temperature ranging of $20^{\circ} \mathrm{C}$ to $200{ }^{\circ} \mathrm{C}$, indicating that they have semiconducting behavior [21], and are similar to the reported compounds [17a]. The results showed that the conductivities of compounds $\mathbf{2}$ and $\mathbf{3}$ are similar with same cations and similar molecule packing mode. However, it was noted that, with the increase of the temperature, the conductivity of $\mathbf{1}$ became higher than $\mathbf{2 - 3}$, which may be related to the metal Ag owns better electronic conductivity [17a, 21c].

\section{Conclusion}

In summary, this work has demonstrated a simple method of synthesizing functionality inorganic-organic hybrid semiconductor materials $\left\{[\mathrm{bbpyb}] \cdot\left[\mathrm{AgBr}_{3}\right]\right\}_{\mathrm{n}}$ (1) $[1,3-\mathrm{PMBP}]\left[\mathrm{Zn}_{2} \mathrm{Cl}_{5.1} \mathrm{Br}_{0.9}\right]$ (2) and [1, 3-PMBP] $\left.\mathrm{Zn}_{2} \mathrm{Br}_{6}\right]$ (3) based on metal 
halides and functional organic viologen derivatives. The results showed that the close proximity of inorganic and organic components can obtain interesting and multifunctional supramolecular frameworks and control the optical and electronic properties. And these good results highlighted that self-assembly of the multifunctional materials via supramolecular design and aggregates was so selective and simple pathway.

\section{Acknowledgements}

Research efforts in the Niu group are supported by the National Science Foundation of China (No. 21171148).

\section{References}

[1] (a) Q.C. Zhang, T. Wu, X.H. Bu, T. Tran, P.Y. Feng, Chem. Mater. 20 (2008) 4170-4172;

(b) X. Zhang, M. Hejazi, S.J. Thiagarajan, W.R. Woerner, D. Banerjee, T.J. Emge, W.Q. Xu, S.J. Teat, Q.H. Gong, A. Safari, R.G. Yang, J.B. Parise, J. Li, J. Am. Chem. Soc. 135 (2013) 17401-17407;

(c) L.M. Wu, X.T. Wu, L. Chen, Coor. Chem. Rev. 253 (2009) 2787-2804;

(d) N. Mercier, N. Louvain, W. Bi, CrystEngComm 11 (2009) 720-734;

(e) Y. Kang, F. Wang, J. Zhang, X.H. Bu, J. Am. Chem. Soc. 134 (2012) 17881-17884;

(f) F.L. Hu, Y.X. Shi, H.H. Chen, J.P. Lang, Dalton Trans. 44 (2015) 18795-18803.

[2] (a) J. Huang, B.G. Peng, W.N. Wang, H.X. Ji, L.L. Li, K. Xi, W.Y. Lai, X.W. Zhang, X.D. Jia, Adv. Funct. Mater. 26 (2016) 1646-1655;

(b) N.V. Lakshmi, T.M. Babu E. Prasad, Chem. Commun. 52 (2016) 617-620;

(c) P. Thoniyot, M.J. Tan, A.A. Karim, D.J. Young X.J. Loh, Adv. Sci. 2 (2015) $1400010(1-13)$;

(d) G.L. Pascal, M. Isabelle, L. Christine, Coor. Chem. Rev. 308 (2016) 381-394;

(e) S. Sourisseau, N. Louvain, W.H. Bi, N. Mercier, D. Rondeau, F. Boucher, J.Y. 
Buzare, C. Legein, Chem. Mater. 19 (2007) 600-607.

[3] (a) K. Pradeesh, K.N. Rao, G.V. Prakash, J. Appl. Phys. 113 (2013) 083523 (1-9);

(b) B. Guzelturk, H.V. Demir, J. Phys. Chem. Lett. 6 (2015) 2206-2215;

(c) L.Z. Cai, Q.S. Chen, C.J. Zhang, P.X. Li, M.S. Wang, G.C. Guo, J. Am. Chem. Soc. 137 (2015) 10882-10885;

(d) S.J. Zhang, G. Lanty, J.S. Lauret, E. Deleporte, P. Audebert, L. Galmiche, Acta Materialia 57 (2009) 3301-3309;

(e) G.E. Wang, M.S. Wang, M.J. Zhang, L.Z. Cai, B.W. Liu, C.J. Zhang, G.C. Guo, J.S. Huang, Inorg. Chem. Commun. 23 (2012) 137-141;

(f) H.Y. Li, Y.L. Wei, X.Y. Dong, S.Q. Zang, T.C. W. Mak, Chem. Mater. 27 (2015) $1327-1331$.

[4] (a) Y.G. Ha, K. Everaerts, M.C. Hersam, T.J. Marks, Acc. Chem. Res. 47 (2014) 1019-1028;

(b) C. Draxl, D. Nabok, ～K. Hannewald, Acc. Chem. Res. 47 (2014) 3225-3232;

(c) H. USTA, A. FACCHETTI, T.J. MARKS, Acc. Chem. Res. 44 (2011) 501-510.

[5] (a) Z.Y. Fu, J. Zhang, Y. Zeng, Y. Tan, S.J. Liao, H.J. Chen, J.C. Dai, CrystEngComm 14 (2012) 786-788;

(b) W. Yu, X.Y. Wang, J. Li, Z.T. Li, Y K. Yan, W. Wang, J. Pei, Chem. Commun. 49 (2013), 54-56.

[6] (a) H.H. Li, Y.J. Wang, H.J. Dong, Z.R. Chen, Y.L. Wu, M. Wang ,S.W. Huang, CrystEngComm 13 (2011) 1778-1781;

(b) Q.X. Yao, Z.F. Ju, X.H. Ji, J. Zhang, Inorg. Chem. 48 (2009) 1266-1268;

(c) X.H. Jin, J.K. Sun, X.M. Xu, Z.H. Li, J. Zhang, Chem. Commun. 46 (2010) 4695-4697;

(d) C.Y. Moon, G.M Dalpian, Y. Zhang, S.H. Wei, X.Y. Huang, J. Li, Chem. Mater. 18 (2006) 2805-2809;

(e) H.J. Chen, M. Li, G.M. Zheng, Y.F. Wang, Y. Song, C.H. Han, Z.Y. Fu, S.J. Liao, J.C. Dai, RSC Adv. 4 (2014) 42983-42990;

(f) S. Sengupta, A. Goswami, R. Mondal, New J. Chem. 38 (2014) 2470-2479. 
[7] H.H. Li, Z.R. Chen, J.Q. Li, C.C. Huang, Y.F. Zhang, G.X. Jia, Eur. J. Inorg. Chem. (2006) 2447-2453.

[8] Y. Chen, Z. Yang, C.X. Guo, C.Y. Ni, Z.G. Ren, H.X. Li, J.P. Lang, Eur. J. Inorg. Chem. (2010) 5326-5333.

[9] A. Pace, E.L. Clennan, F. Jensen, J. Singleton, J. Phys. Chem. B 108 (2004) 4673-4678.

[10] (a) Q.C. Zhang, T. Wu, X H. Bu, T. Tran, P.Y. Feng, Chem. Mater. 20 (2008) 4170-4172;

(b) C.S. Kim, S. Lee, L.L. Tinker, S. Bernhard, Y L. Loo, Chem. Mater. 21 (2009) 4583-4588;

(c) S.S. Jang, Y.H. Jang, Y.H. Kim, W.A. Goddard III, A.H. Flood, B.W. Laursen, H.R. Tseng, J.F. Stoddart, J.O. Jeppesen, J.W. Choi, D.W. Steuerman, E. Delonno, J.R. Heath, J. AM. CHEM. SOC. 127 (2005) 1563-1575;

(d) X.H. Xu, K. Shreder, B L. Iverson, A.J. Bard, J. Am. Chem. Soc. 118 (1996) 3656-3660.

[11] H.J. Du, W.L. Zhang, C.H. Wang, Y. Li, Y.Y. Niu, H.W. Hou, Inorg. Chem. Commun. 54 (2015) 45-49.

[12] (a) J.W. Zhang, Y.L. Liu, G.L. Wang, M. Schonhoff, X. Zhang, Langmuir 27 (2011) 10370-10375;

(b) W. Geuder, S. Hunig, A. Suchy, Tetrahedran. 42 (1986) 1665-1677.

[13] O.V. Dolomanov, L.J. Bourhis, R.J. Gildea, J.A.K. Howard, H. Puschmann, J. Appl. Cryst. 42 (2009) 339.

[14] (a) R.G. Lin, G. Xu, M.S. Wang, G. Lu, P.X. Li, G.C. Guo, Inorg. Chem. 52 (2013) 1199-1205;

(b) X.Y. Lv, M.S. Wang, C. Yang, G.E. Wang, S.H. Wang, R.G. Lin, G.C. Guo, Inorg. Chem. 51 (2012) 4015-4019;

(c) G. Xu, G.C. Guo, M.S. Wang, Z.J. Zhang, W.T. Chen, J.S. Huang, Angew. Chem. Int. Ed. 46 (2007) 3249-3251;

(d) Z.J. Zhang, S.C. Xiang, G.C. Guo, G. Xu, M.S. Wang, J.P. Zou, S.P. Guo, J.S. 
Huang, Angew. Chem. Int. Ed. 47 (2008) 4149-4152;

(e) P.X. Li, M.S. Wang, M.J. Zhang, C.S. Lin, L.Z. Cai, S.P. Guo, G.C. Guo, Angew. Chem. Int. Ed. 53 (2014) 11529-11531;

(f) P.X. Li, M.S. Wang, L.Z. Cai, G.E. Wang, G.C. Guo, J.Mater. Chem. C 3 (2015) 253-256.

[15] (a) A. Neuba, O. Seewald, U. Florke, G. Henkel, Acta Cryst. E63 (2007) m2099-2100;

(b) J.H. Goh, H.K. Fun, Nithinchandra, B. Kalluraya, Acta Cryst., E66 (2010) o1225-1226.

[16] (a) Y. Xia, P F. Wu, Y.G. Wei, Y. Wang, H.Y. Guo, Cryst. Growth Des. 6 (2006) 253-257;

(b) H.Y. Liu, L. Bo, J. Yang, Y.Y. Liu, J.F. Ma, H. Wu, Dalton Trans.40 (2011) 9782-9788.

[17] (a) G. Givaja, P. Amo-Ochoa, C.J. Gomez-Garcia, F. Zamora, Chem. Soc. Rev. 41 (2012) 115-147;

(b)H.H. Li, Z.R. Chen, L.G. Sun, Z.X. Lian, X.B. Chen, J.B. Li, J.Q. Li, Cryst. Growth Des. 10 (2011) 1068-1073.

[18] (a) T.B. Faust, D.M.D’Alessandro, RSC Adv. 4 (2014) 17498-17512;

(b) S.K. Mandal, M.E. Itkis, X.L. Chi, S. Samanta, D. Lidsky, R.W. Reed, R.T. Oakley, F.S. Tham, R.C. Haddon, J. AM. CHEM. SOC. 127 (2005) 8185-8196;

(c) Z. Chen, J. Zhang, M. Song, J. Yin, G.A. Yu, S.H. Liu, Chem. Commun. 51 (2015) 326-329;

(d) J.H. Liang, Z. Chen, L.J. Xu, J. Wang, J. Yin, G.A. Yu, Z.N. Chen, S.H. Liu, J. Mater. Chem. C. 2 (2014) 2243-2250;

(e) Z. Chen, D. Wu, X. Han, J.H. Liang, J. Yin, G.A. Yu, S.H. Liu, Chem. Commun. 50 (2014) 11033-11035.

[19] (a) H.W. Hou, H.G. Ang, S.G. Ang, Y.T. Fan, M.K.M. Low, W. Ji, Y.W. Lee, Phys. Chem. Chem. Phys. 1 (1999) 3145-3149;

(b) M. Sheik-Bahae, A.A. Said, T.H. Wei, D.J. Hagan, E.W. Van Stryland, IEEE J, 
Quantum Electron. 26 (1990) 760-769;

(c) A.J. Wang, Y. Wang, W. Yu, Z.P. Huang, Y. Fang, L.L. Long, Y.L. Song, M P. Cifuentes, M.G. Humphrey, L. Zhang, J.D. Shao, C. Zhang, RSC Adv. 6 (2016) 20120-20127;

(d) Y. Fang, J.Y. Yang, Y. Yang, X.Z. Wu, Z.G. Xiao, F. Zhou, Y.L. Song, J. Phys. D: Appl. Phys.49( 2016) 045105(1-6);

(e) J. Qu, Y.L. Song, W. Ji, S. Jing, D.R. Zhu, W. Huang, M.X. Zheng, Y.L. Li, J. Ma, Dalton Trans.45 (2016) 3417-3428.

[20] (a) L. Jiang, F.S. Lu, H M. Li, Q. Chang, Y.L. Li, H.B. Liu, S. Wang, Y.L. Song, G.L. Cui, N. Wang, X.R. He, D.B. Zhu, J. Phys. Chem. B 109 (2005) 6311-6315;

(b) Y.Y. Niu, B L. Wu, X.L. Guo, Y.L. Song, X.C. Liu, H.Y. Zhang, H.W. Hou, C.Y. Niu, S.W. Ng, Cryst. Growth Des. 8 (2008) 2393-2401.

[21] (a) Y. Chen, Z.O. Wang, Z. Yang, Z.G. Ren, H.X. Li, J.P. Lang, Dalton Trans. 39 (2010) 9476-9479;

(b) M. Usman, S. Mendiratta, S. Batjargal, G. Haider, M. Hayashi, N.R. Gade, J.W. Chen, Y.F. Chen, K.L. Lu, ACS Appl. Mater. Interfoces 7 (2015) 22767-22774;

(c) P.M. Marley, G.A. Horrocks, K.E. Pelcher, S. Banerjee, Chem. Commun. 51(2015) 5181-5198;

(d) M.M. Chen, B. Wu, Y. Chen, F.L. Li, X.R. Su, J.P. Lang, Chin. Sci. Bull. 59 (2014) 1625-1630. 
Table 1 Crystal data and structure refinement details for 1-3.

\begin{tabular}{|c|c|c|c|}
\hline & 1 & 2 & 3 \\
\hline formula & $\mathrm{C}_{24} \mathrm{H}_{24} \mathrm{AgBr}_{3} \mathrm{~N}_{4}$ & $\mathrm{C}_{28} \mathrm{H}_{24} \mathrm{Br}_{0.94} \mathrm{Cl}_{5.06} \mathrm{~N}_{4} \mathrm{Zn}_{2}$ & $\mathrm{C}_{28} \mathrm{H}_{24} \mathrm{Br}_{6} \mathrm{~N}_{4} \mathrm{Zn}_{2}$ \\
\hline formula weight & 716.07 & 801.63 & 1026.71 \\
\hline crystal system & Monoclinic & Monoclinic & Monoclinic \\
\hline space group & $C 2 / c$ & $P 2_{1} / \mathrm{n}$ & $P 2_{1} / \mathrm{n}$ \\
\hline$a / \AA$ & $11.6022(5)$ & $7.3266(2)$ & 7.30703(9) \\
\hline$b / \AA$ & $20.9306(10)$ & $29.6698(10)$ & $30.4953(4)$ \\
\hline$c / \AA$ & $10.3158(5)$ & $14.9971(4)$ & $15.1713(2)$ \\
\hline$\alpha / \operatorname{deg}$ & 90 & 90.00 & 90.00 \\
\hline$\beta / \operatorname{deg}$ & $103.875(5)$ & $94.286(3)$ & $95.2558(12)$ \\
\hline$\gamma / \operatorname{deg}$ & 90 & 90.00 & 90.00 \\
\hline $\mathrm{vol} / \AA^{3}$ & $2432.0(2)$ & $3250.94(18)$ & $3366.42(7)$ \\
\hline$Z$ & 4 & 4 & 4 \\
\hline$D_{\mathrm{c}} / \mathrm{g} \mathrm{cm}^{-3}$ & 1.956 & 1.638 & 2.026 \\
\hline$\mu / \mathrm{mm}^{-1}$ & 5.778 & 7.193 & 10.290 \\
\hline $\mathrm{F}(000)$ & 1392 & 1596.0 & 1960.0 \\
\hline rflns collected & 5228 & 11633 & 13116 \\
\hline unique rflns & 2482 & 5783 & 6475 \\
\hline GOF & 1.026 & 1.040 & 1.024 \\
\hline $\mathrm{R}_{1}^{\mathrm{a}}(I>2 o ́(I))$ & 0.0488 & 0.0561 & 0.0487 \\
\hline$w_{2}{ }^{a}$ (all data) & 0.1060 & 0.1831 & 0.1402 \\
\hline$\Delta \rho \max / \Delta \rho \min \left(\mathrm{e}^{-3}\right)$ & $1.52 /-1.72$ & $1.51 /-0.48$ & $1.15 /-0.64$ \\
\hline
\end{tabular}

${ }^{a} \mathrm{R}_{1}=\| F_{\mathrm{O}}|-| F \mathrm{c}|||F \mathrm{O}| ; \mathrm{wR}_{2}=\left[w\left(F \mathrm{O}^{2}-F \mathrm{c}^{2}\right)^{2} / w\left(F_{\mathrm{O}}{ }^{2}\right)^{2}\right]^{1 / 2}$ 


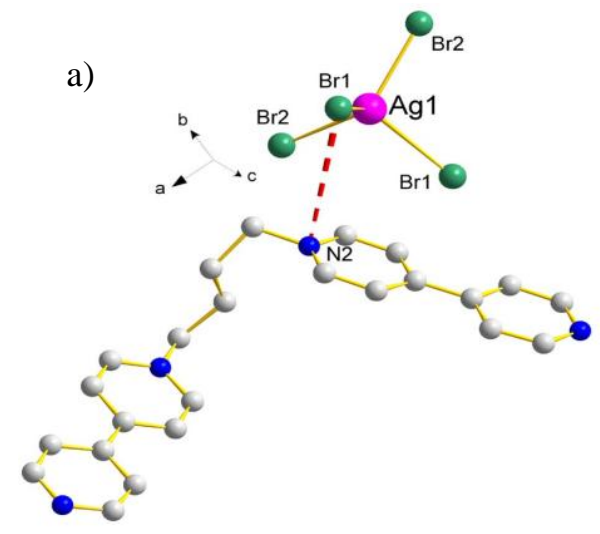

b)
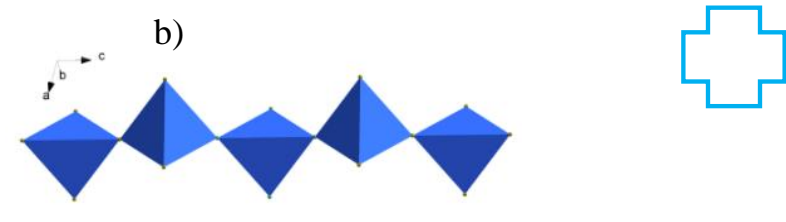

c)
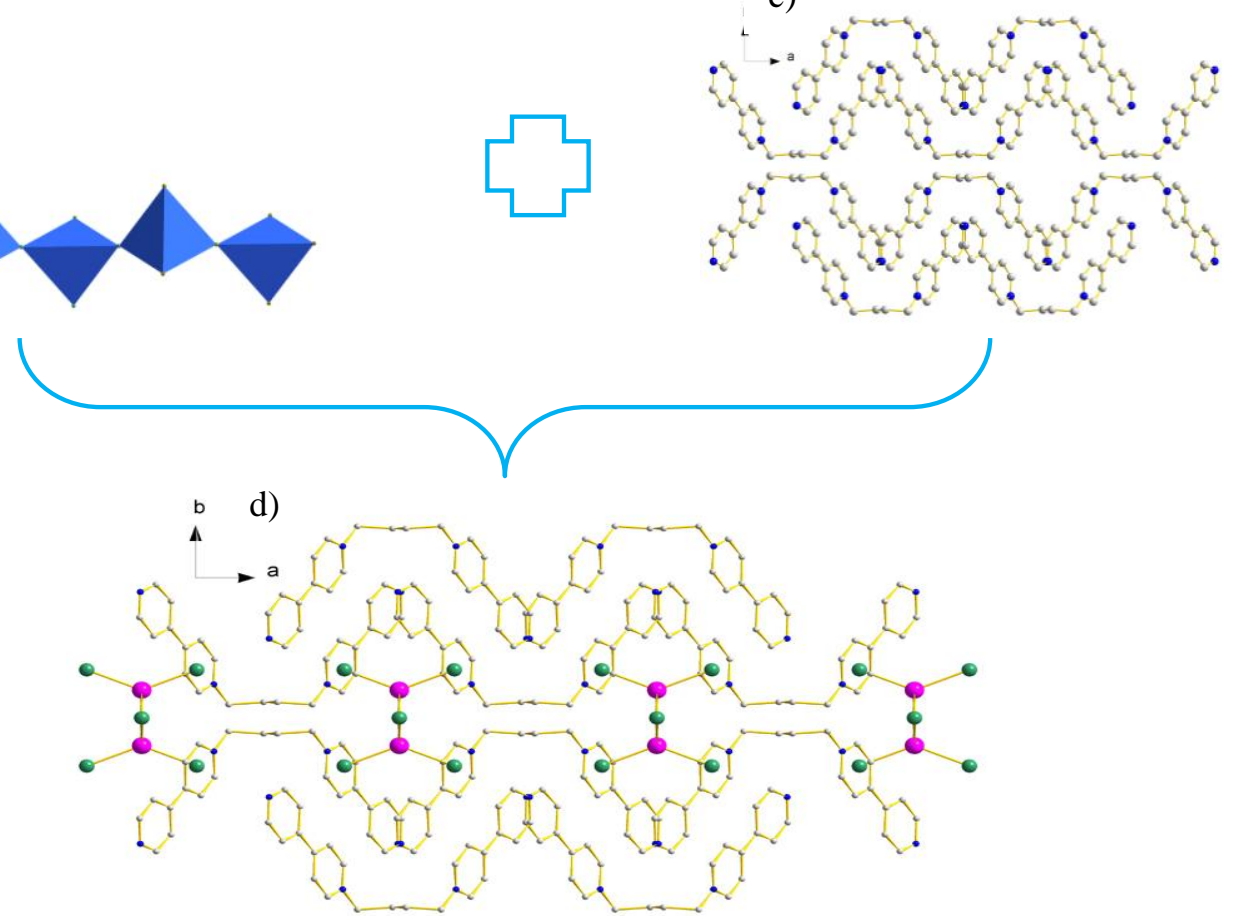

e)
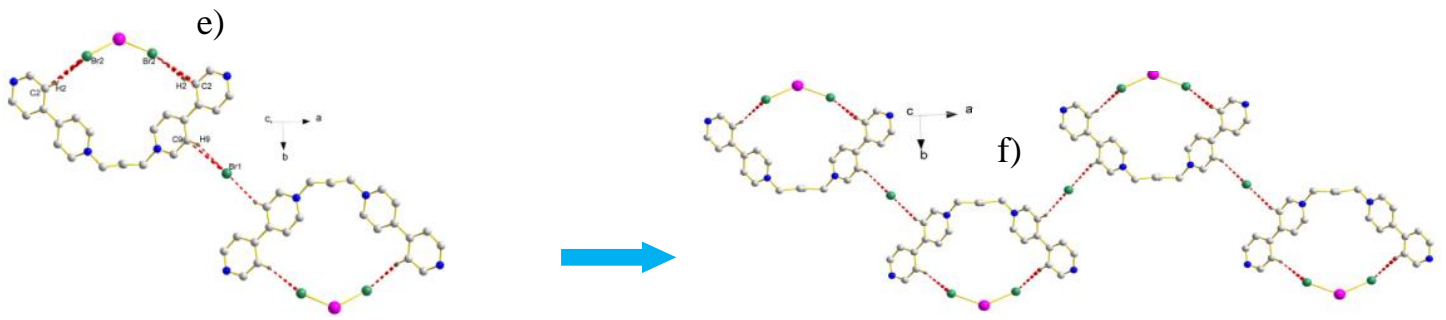

Fig.1 a) Structure of compound 1 with atomic labeling. All $\mathrm{H}$ atoms were omitted for clarity. b) 1D infinite polyhedral chain in 1. c) a view of cations threaded network. d) the ball-and-stick packing of compound 1. e) a view of hydrogen bonds of compound 1. f) $1 \mathrm{D}$ inorganic-organic hybrid chain constructed by hydrogen bonds. 

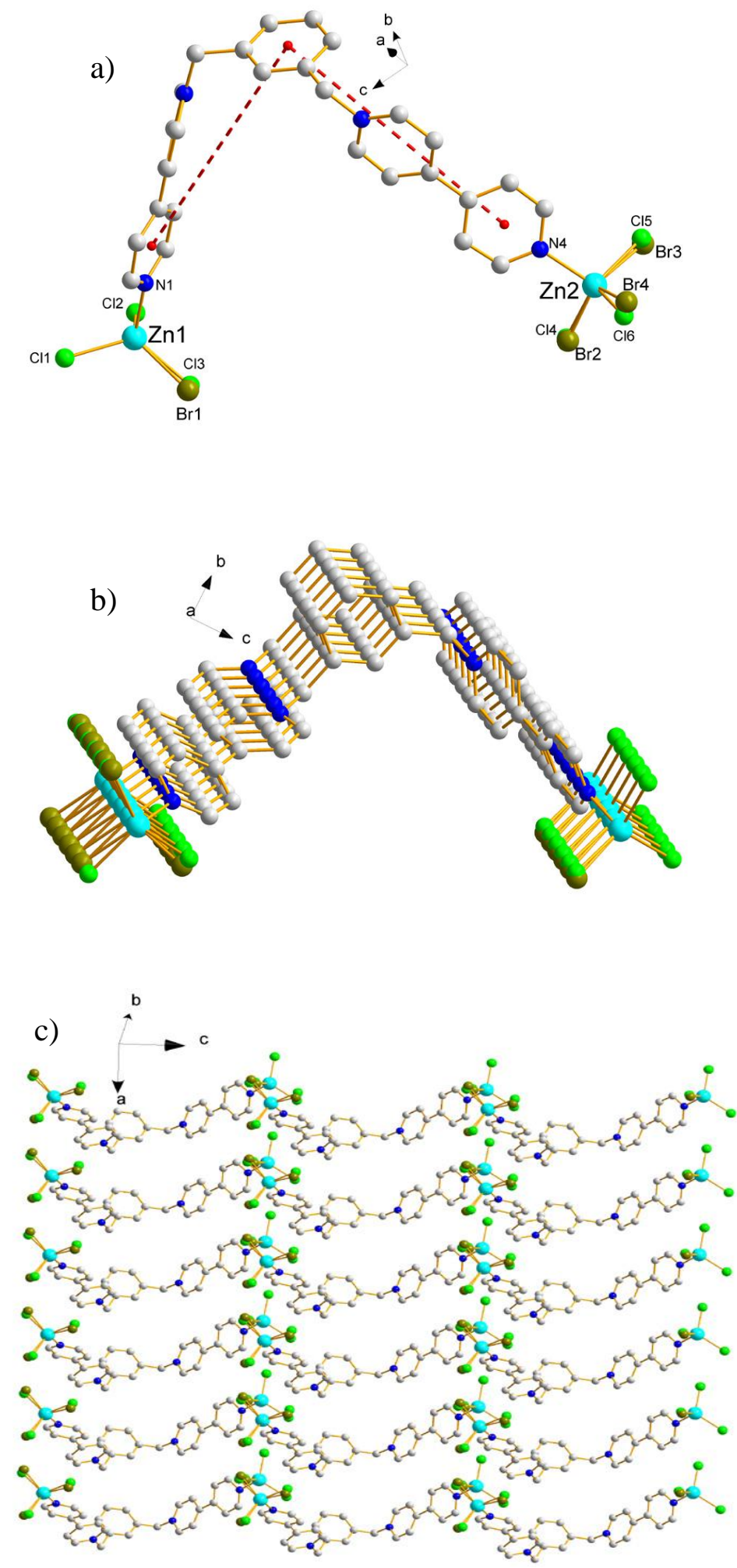

Fig.2 a) Structure of compound 2 with atomic labeling. All $\mathrm{H}$ atoms were omitted for clarity. b) A 1D inorganic-organic hybrid chain in 2. c) A view of 2D supermolecular architecture of compound 2. 

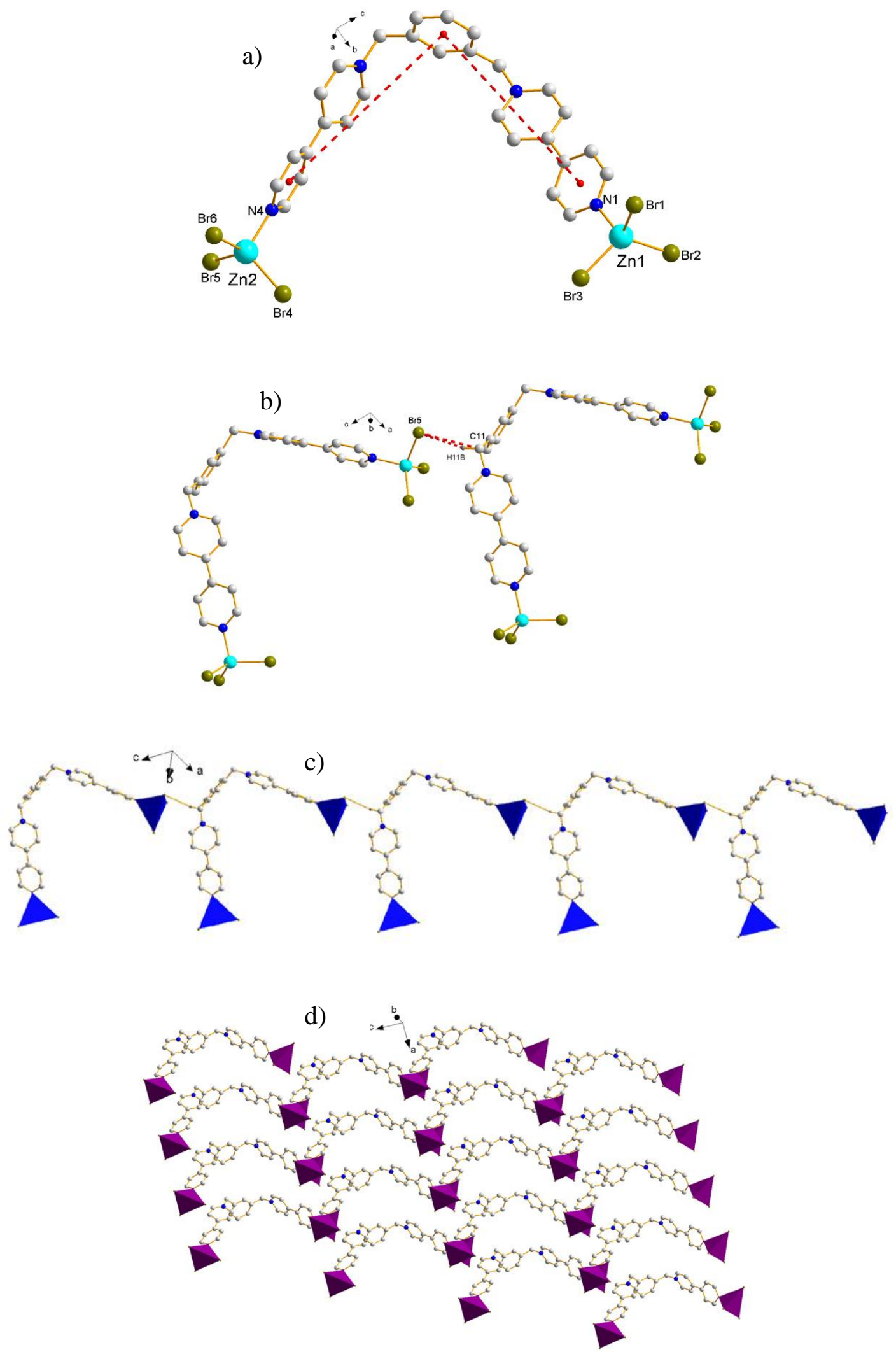

Fig.3 a) Structure of compound 3 with atomic labeling. All $\mathrm{H}$ atoms were omitted for clarity. b) a view of hydrogen bonds of compound 3. c) 1D inorganic-organic hybrid chain constructed by hydrogen bonds. d) The ball-and-stick packing of compound $\mathbf{3}$. 

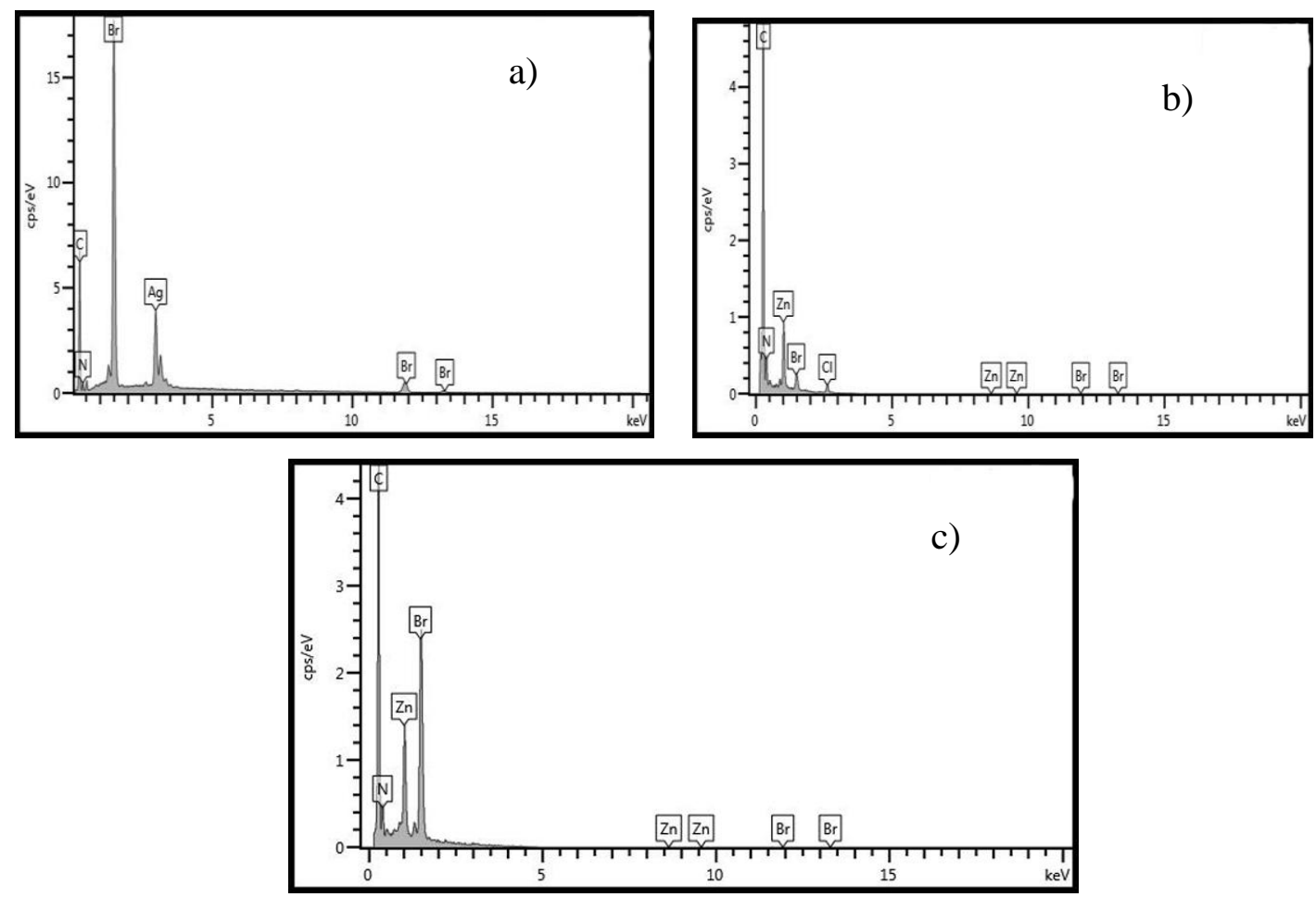

Fig. 4 a) EDX pattern of compound 1; b) EDX pattern of compound 2; c) EDX pattern of compound $\mathbf{3}$. 

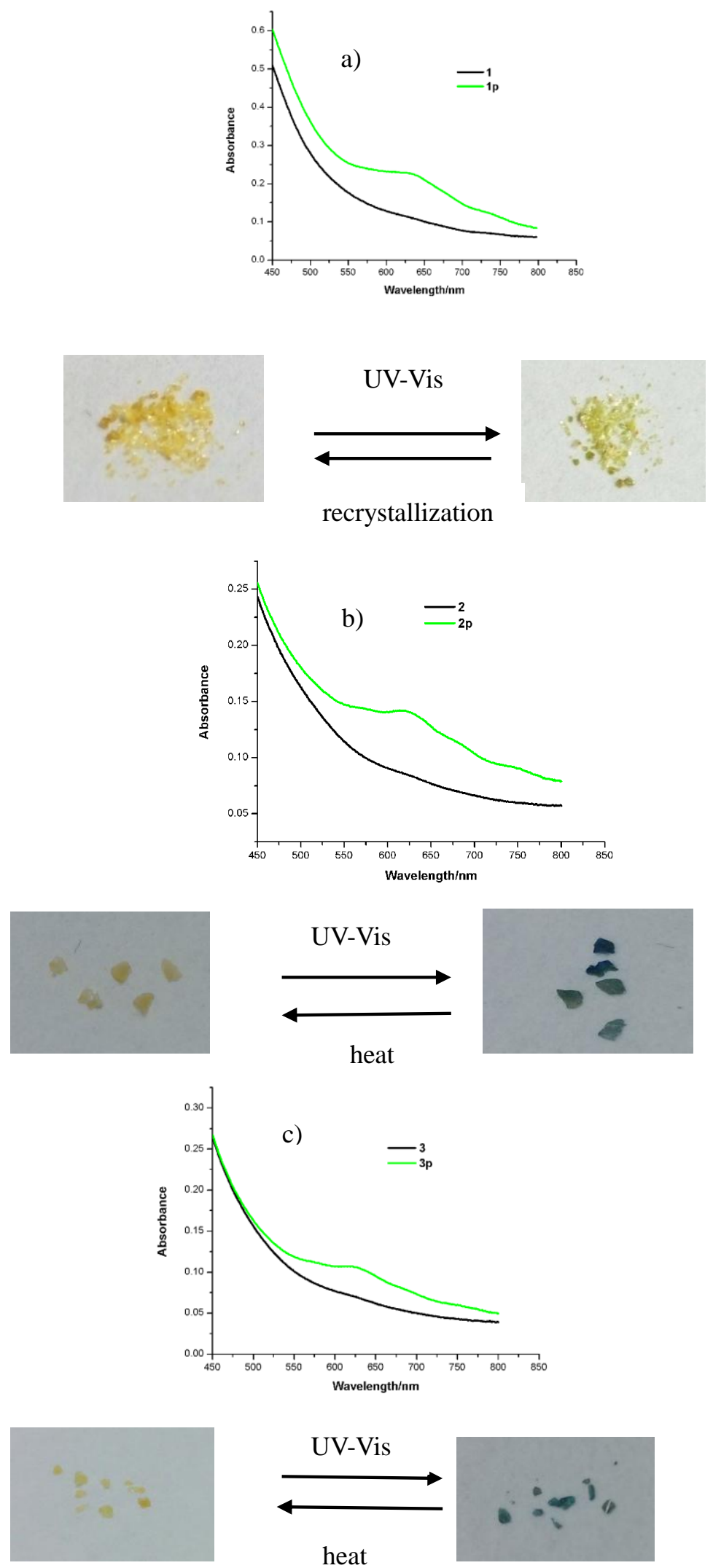

Fig. 5 Diffuse reflectance spectra and photographs showing the photochromic behaviors of compounds 1-3. 

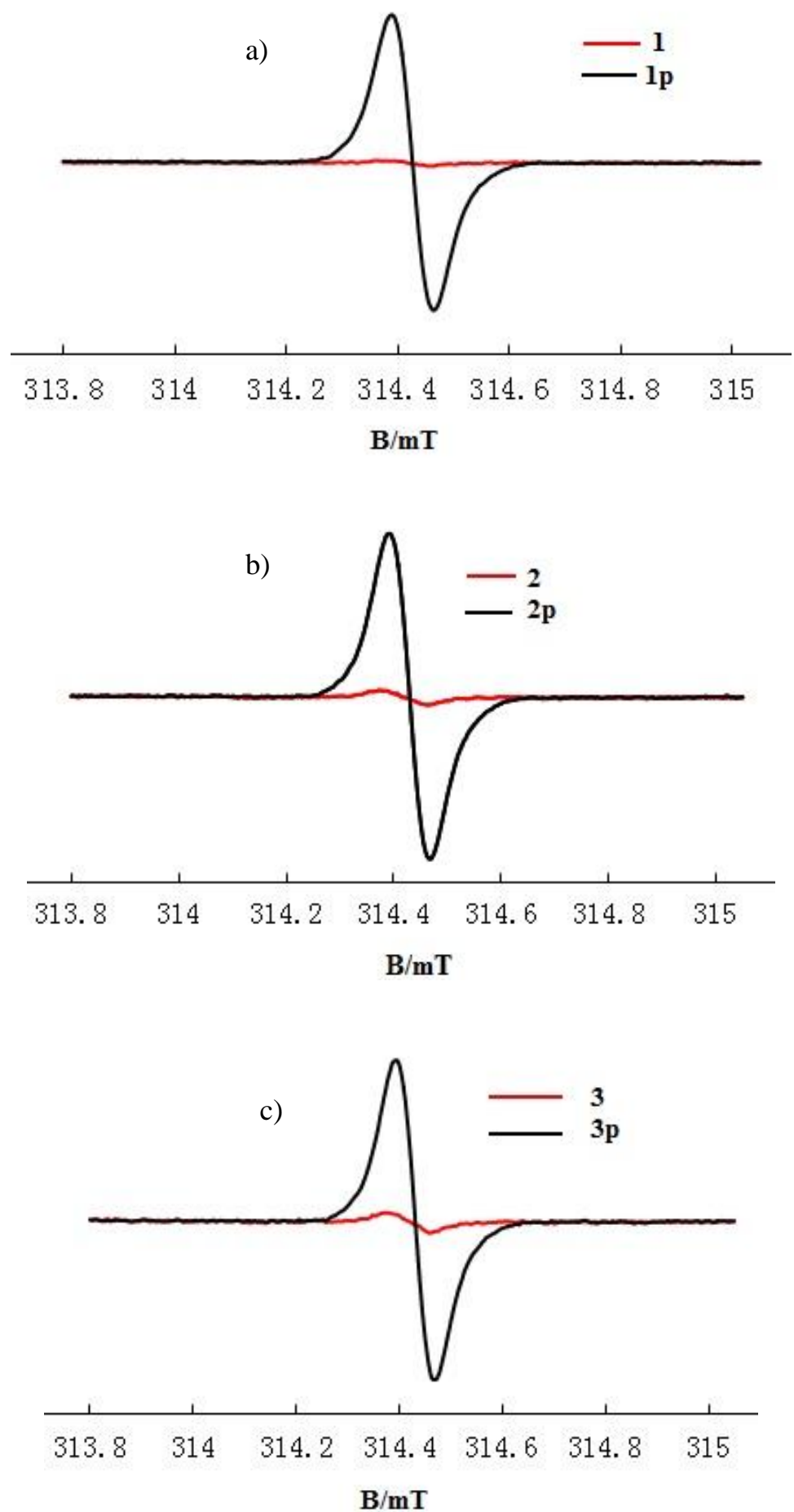

Fig. 6 ESR spectra for 1-3 and 1p-3p before and after irradiation. 

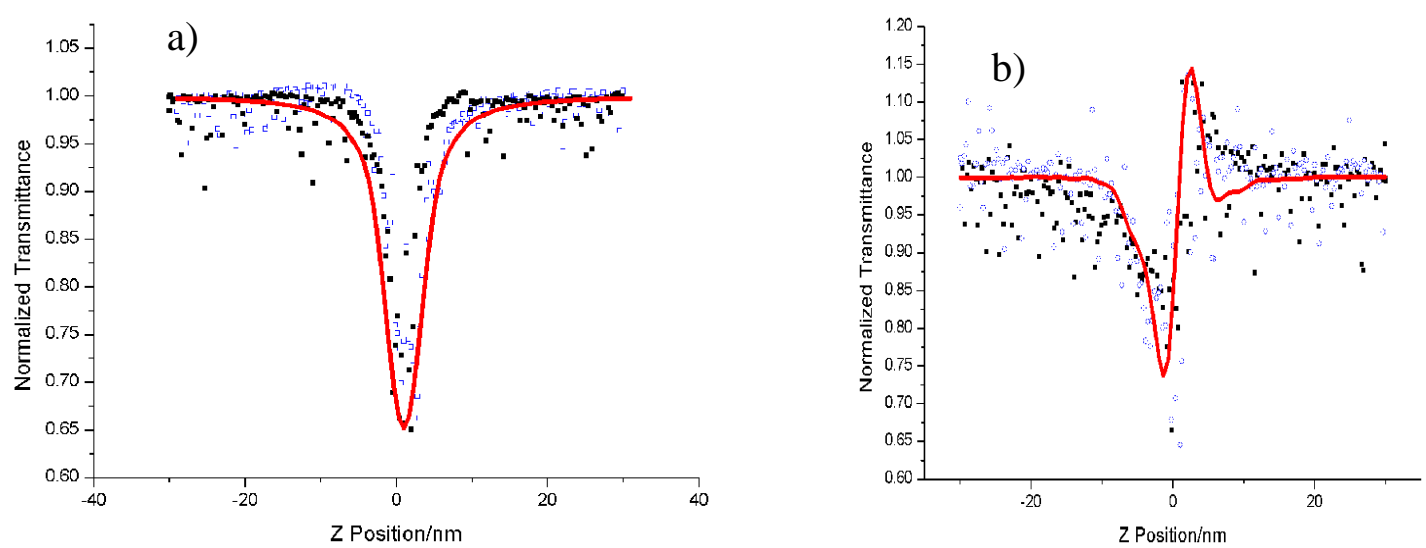

Fig. 7. Z-Scan experiment of compound 1 in DMSO solution and pure DMSO at 532 nm: (a) open-aperture Z-scan curve of the compound 1; (b) closed-aperture Z-scan curve of the compound $\mathbf{1}$. 

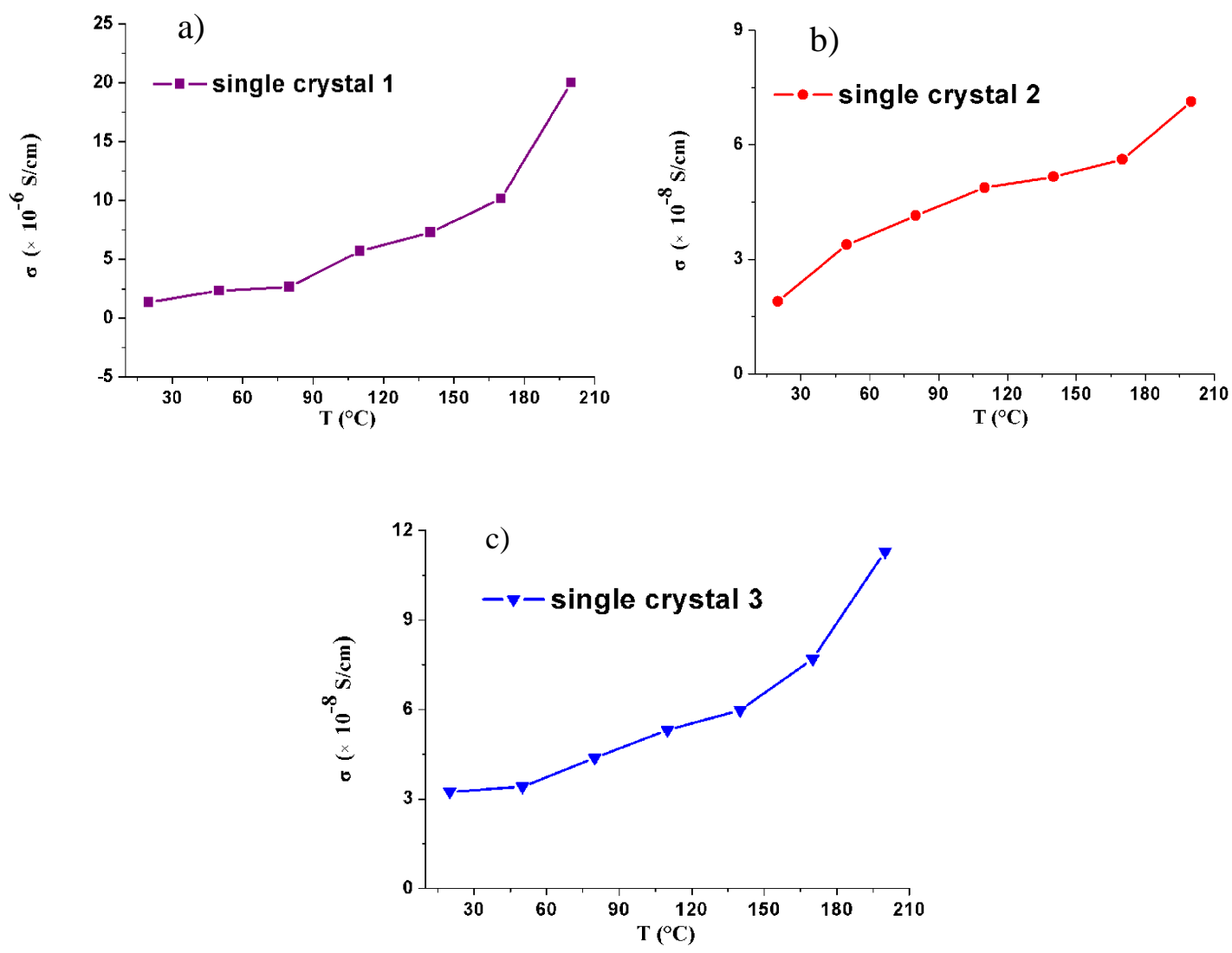

Fig. 8. Temperature dependence of the electrical conduntivity of the single crystals of 1 (a), 2 (b) and 3 (c). 


\section{Figure Captions}

Fig.1 a) Structure of compound 1 with atomic labeling. All $\mathrm{H}$ atoms were omitted for clarity. b) 1D infinite polyhedral chain in 1. c) a view of cations threaded network. d) the ball-and-stick packing of compound 1. e) a view of hydrogen bonds of compound 1. f) $1 \mathrm{D}$ inorganic-organic hybrid chain constructed by hydrogen bonds.

Fig.2 a) Structure of compound 2 with atomic labeling. All $\mathrm{H}$ atoms were omitted for clarity. b) A 1D inorganic-organic hybrid chain in 2. c) A view of 2D supermolecular architecture of compound $\mathbf{2}$.

Fig.3 a) Structure of compound 3 with atomic labeling. All $\mathrm{H}$ atoms were omitted for clarity. b) a view of hydrogen bonds of compound 3. c) 1D inorganic-organic hybrid chain constructed by hydrogen bonds. d) The ball-and-stick packing of compound $\mathbf{3}$.

Fig. 4 a) EDX pattern of compound 1; b) EDX pattern of compound 2; c) EDX pattern of compound 3 .

Fig. 5 Diffuse reflectance spectra and photographs showing the photochromic behaviors of compounds 1-3.

Fig. 6 ESR spectra for 1-3 and 1p-3p before and after irradiation.

Fig. 7 Z-Scan experiment of compound 1 in DMSO solution and pure DMSO at 532 nm: (a) open-aperture Z-scan curve of the compound 1; (b) closed-aperture Z-scan curve of the compound $\mathbf{1}$.

Fig. 8. Temperature dependence of the electrical conduntivity of the single crystals of 1 (a), 2 (b) and 3 (c). 